\title{
Psychotropic medication before and after disability retirement by pre-retirement perceived work-related stress
}

DOI:

10.1093/eurpub/ckz131

10.1093/eurpub/ckz131

\section{Document Version}

Accepted author manuscript

Link to publication record in Manchester Research Explorer

\section{Citation for published version (APA):}

Halonen, J. I., Chandola, T., Hyde, M., Leinonen, T., Westerlund, H., Aalto, V., Pentti, J., Laaksonen, M., Stenholm, S., Mänty, M., Vahtera, J., Oksanen, T., Kivimäki, M., Virtanen, M., \& Lallukka, T. (2019). Psychotropic medication before and after disability retirement by pre-retirement perceived work-related stress. European Journal of Public Health . https://doi.org/10.1093/eurpub/ckz131, https://doi.org/10.1093/eurpub/ckz131

\section{Published in:}

European Journal of Public Health

\section{Citing this paper}

Please note that where the full-text provided on Manchester Research Explorer is the Author Accepted Manuscript or Proof version this may differ from the final Published version. If citing, it is advised that you check and use the publisher's definitive version.

\section{General rights}

Copyright and moral rights for the publications made accessible in the Research Explorer are retained by the authors and/or other copyright owners and it is a condition of accessing publications that users recognise and abide by the legal requirements associated with these rights.

\section{Takedown policy}

If you believe that this document breaches copyright please refer to the University of Manchester's Takedown Procedures [http://man.ac.uk/04Y6Bo] or contact uml.scholarlycommunications@manchester.ac.uk providing relevant details, so we can investigate your claim.

\section{OPEN ACCESS}




\section{OXFORD}

\section{European Journal of Public Health}

\section{Psychotropic medication before and after disability retirement by pre-retirement perceived work-related stress}

\begin{tabular}{|c|c|}
\hline Journal: & European Journal of Public Health \\
\hline Manuscript ID & EJPH-2018-12-OM-1070.R2 \\
\hline Manuscript Type: & Original Manuscript \\
\hline $\begin{array}{r}\text { Date Submitted by the } \\
\text { Author: }\end{array}$ & $n / a$ \\
\hline Complete List of Authors: & $\begin{array}{l}\text { Halonen, Jaana; Finnish Institute of Occupational Health, Work } \\
\text { Organizations } \\
\text { Chandola, Tarani ; University of Manchester, School of Social Sciences } \\
\text { Hyde, Martin; Swansea University, Centre for Innovative Ageing } \\
\text { Leinonen, Taina } \\
\text { Westerlund, Hugo; Stress Research Institute, Stockholm University, } \\
\text { Aalto, Ville } \\
\text { Pentti, Jaana; University of Turku and Turku University Hospital, } \\
\text { Department of Public Health } \\
\text { Laaksonen, Mikko; Finnish Centre for Pensions, } \\
\text { Stenholm, Sari; Turun Yliopisto } \\
\text { Mänty, Minna; University of Helsinki, Department of Public Health } \\
\text { Vahtera, Jussi; Turun Yliopisto, Department of Public Health } \\
\text { Oksanen, Tuula; Finnish Institute of Occupational Health, Work \& } \\
\text { Organisations } \\
\text { Kivimäki, Mika; University College London; Helsingin Yliopisto } \\
\text { Laaketieteellinen tiedekunta; Finnish Institute of Occupational Health, } \\
\text { Work Organizations } \\
\text { Virtanen, Marianna; University of Eastern Finland, School of Educational } \\
\text { Sciences and Psychology; Uppsala University } \\
\text { Lallukka, Tea; Finnish Institute of Occupational Health, }\end{array}$ \\
\hline Keywords: & disability retirement, mental health, medication use, work-related stress \\
\hline
\end{tabular}

\section{SCHOLARONE Manuscripts}


Original article: European Journal of Public Health

\section{Psychotropic medication before and after disability retirement by pre-retirement perceived work-related stress}

Halonen JI, ${ }^{1,2}$ Chandola T, ${ }^{3}$ Hyde $\mathrm{M},{ }^{3}$ Leinonen T, ${ }^{1}$ Westerlund $\mathrm{H},{ }^{2}$ Aalto V, ${ }^{1}$ Pentti

J, ${ }^{4,5}$ Laaksonen M, ${ }^{6}$ Stenholm S, ${ }^{4}$ Mänty $M,{ }^{7}$ Vahtera J, ${ }^{4}$ Oksanen T, ${ }^{1}$ Kivimäki M, $, 15,8$

Virtanen M,,$^{29}$ Lallukka $\mathrm{T}^{1,5}$

1 Finnish Institute of Occupational Health, Helsinki, Finland

2 Stress Research Institute, Stockholm University, Stockholm, Sweden

3 Centre for Innovative Ageing, Swansea University, UK 4 Department of Public

Health, University of Turku and Turku University Hospital, Turku, Finland

5 Department of Public Health, University of Helsinki, Helsinki, Finland

6 Finnish Center for Pension, Helsinki, Finland

7 Laurea University of Applied Sciences, Vantaa, Finland

8 Department of Epidemiology and Public Health, University College London, UK

$9 \underline{\text { School of Educational Sciences and Psychology, University of Eastern Finland, }}$ Joensuu, Finland

Corresponding author: Jaana I. Halonen, address: Finnish Institute of Occupational Health, 70032 TYÖTERVEYSLAITOS, Finland

E-mail: jaana.halonen@ttl.fi

Telephone: +358438244264

Words $2 \underline{829784 / 3000}$ 


\begin{abstract}
(250/250)
Background Retirement has been associated with improved mental health, but it is unclear how much this is due to the removal of work-related stressors. We examined rates of psychotropic medication use before and after the transition to disability retirement due to mental, musculoskeletal, and other causes by pre-retirement levels of perceived work stress (effort-reward imbalance, ERI).

Methods Register-based date and diagnosis of disability retirement of 2766 participants of the Finnish Public Sector study cohort were linked to survey data on ERI, social- and health-related covariates, and to national records on prescribed reimbursed psychotropic medication, measured as defined daily doses (DDDs). Follow-up for DDDs was two to five years before and after disability retirement. We assessed differences in the levels of DDDs before and after retirement among those with high versus low level of pre-retirement ERI with repeated measures regression. Results Those with high (vs. low) levels of ERI used slightly more psychotropic medication before disability retirement due to mental disorders (rate ratio (RR) 1.14, 95\% CI 0.94-1.37), but after retirement this difference attenuated (RR 0.94, 95\% $0.80-1.10, \mathrm{p}$ for interaction 0.02 ). Such a change was not observed for the other causes of disability retirement.
\end{abstract}

Conclusions The level of psychotropic medication use over the transition to disability retirement due to mental, but not musculoskeletal or other, causes was modified by pre-retirement perceived work-related stress. This suggests that among people retiring due to mental disorders those who had stressful jobs benefit from retirement more than those with low levels of work-related stress.

Key words: disability retirement; mental health; medication use; perceived workrelated stress 


\section{Introduction}

Mental disorders are highly prevalent among employed people, and are one of the main reasons for early exit from paid employment in Finland. ${ }^{1}$ Previous studies have shown that a key indicator of mental disorders, namely psychotropic medication use, tends to increase before the transition to disability retirement followed by decrease after the transition, particularly if retirement was due to mental disorders. ${ }^{2-5}$ Moreover, in some studies this decrease has been greater among people from a higher socioeconomic background, ${ }^{3}$ suggesting that socioeconomic differences in workrelated exposures may modify changes in psychotropic medication use around the retirement period. Some studies from Asia found that mental health problems may increase after transition from work to non-work, ${ }^{6}$ and voluntary ${ }^{7}$ or non-voluntary retirement, ${ }^{8}$ but at least in three European studies, retirement has been associated with a decrease in mental fatigue ${ }^{9}$ and sleep disturbances ${ }^{10,11}$ and an improvement in mental well-being. ${ }^{12}$ Improvements in self-rated health in general as well as in mental health, as indicated by sleep quality, have been found to be greater for people with highly demanding but non-satisfying jobs compared to those working in less stressful jobs. ${ }^{10,11,13}$ This suggests that relief from stressful working conditions, that naturally occurs at retirement, could positively affect mental health. ${ }^{14}$ However, this hypothesis has not been tested in relation to psychotropic medication use as most previous studies on medication use have been register-based, and thus have lacked data on perceived work stress.

Thus, we examined whether psychotropic medication before and after the transition to disability retirement differ between employees with high versus low levels of pre-retirement effort-reward imbalance (ERI), i.e. perceived work-related stress. We used ERI as according to a recent review it is associated with an increased 
risk of depressive disorders. ${ }^{15}$ We examined separately disability retirement due to any cause, mental disorders, musculoskeletal diseases, and other reasons. The level of psychotropic medication use was assessed using defined daily dose (DDD). According to WHO, DDD is the assumed average maintenance dose per day for a drug used for its main indication in adults. ${ }^{16}$ Based on the earlier evidence, we hypothesised that there should be a decline in the level of psychotropic medication after the transition to disability retirement, and that this decline is larger among those reporting high versus low levels of ERI prior to the transition.

\section{Material and methods}

The study population consisted of participants of the Finnish Public Sector (FPS) study, a prospective occupational cohort study with identifiable questionnaire surveys. The eligible population of the original cohort included all employees who had been working for a minimum of six months in the target sites; 10 towns and six hospital districts, between 1991 and $2005(n=151$ 901). Nested survey cohorts included all participants who were employed by the participating organizations at the time of the surveys or had participated in a survey while employed, but later left the organizations (i.e. 'leavers' including retirees). The participants are from a wide range of occupations, from administrative personnel and professionals (e.g., doctors) to semiskilled and unskilled workers (e.g., cleaners). Surveys were repeated at 4-year intervals. For this study, all participants of the FPS study cohort who retired due to disability between 2000 and $2009(\mathrm{~N}=3279)$ were included (Figure 1). All of them had register-based follow-up for medication purchases for a minimum of two years before and two years after retirement. All who responded to a questionnaire survey about their perceived work-related stress $(\mathrm{N}=2961)$ and covariates before their 
retirement (survey for current employees in 2000, 2004, or 2008) were included in the analytical sample of 2766 participants. Information on the cause (based on ICD-10 diagnoses) and date of disability retirement was obtained from the Finnish Centre for Pensions. They maintain the register for earnings-related pension schemes, where a disability pension can be granted to a person aged 18-62 years with a work history that has accrued a pension. This disability pension can be granted either as a permanent or as a temporary disability pension. However, it is required that the incapacity to work should last for at least one year. The following ICD-10 codes were used to group the cause-specific disability retirement: F00-99 for mental disorders, and M00-99 for musculoskeletal diseases. These sub-groups were chosen as they are the most common reasons for disability retirement in Finland. ${ }^{1}$ The remaining ICDcodes were grouped as "other causes".

Perceived work-related stress

Perceived work-related stress was defined using reports of effort-reward imbalance in the last survey before retirement. Adapted from the standard 10-item ERI scale, ${ }^{17}$ we used one survey question on efforts, and three questions (Cronbach's $\alpha=0.64$ ) on rewards to assess the level of ERI. The response format for each question was on a 5point Likert scale $(1=$ strongly disagree, $2=$ disagree, $3=$ neither agree nor disagree, 4=agree, and 5=strongly agree) and greater values indicated greater efforts or rewards. The level of ERI was assessed as the ratio of the effort score and the mean reward score. A higher ratio indicated greater imbalance between efforts and rewards. As in prior studies, we used the highest quartile as the cut-off value when defining those reporting high level of ERI. ${ }^{18,19}$ The 4-item abridged scale has a relatively high correlation $(\mathrm{R}=0.6)$ with the 10 -item version of the standard ERI scale. ${ }^{18}$ 


\section{Outcome}

Data for medication purchases were obtained from a national register maintained by the Social Insurance Institution. The register contains the dispensing date and the WHO Anatomical Therapeutic Chemical (ATC) code for all purchased medications reimbursed to Finnish residents in non-institutional settings. All ATC codes for antidepressants (ATC code N06A), anxiolytics (NO5B) and hypnotics (NO5C) were considered as psychotropic medications. For each follow-up year, our medication data included information on annual DDDs for all psychotropic medication purchases two to five years before and after the transition to disability retirement. For each participant we summed DDDs for all the included medication groups. The main outcome was the sum of annual DDDs for any psychotropic medication and this was treated as a discrete count variable.

\section{Covariates}

From the survey data we obtained information about key covariates. Like information about perceived work-related stress, these covariates were taken from the last survey before disability retirement. Time to disability retirement after responding to the survey was on average 2.7 years. In a sensitivity analysis we adjusted for this, but as it had only a negligible effect on the associations, it was excluded from the final models. Based on prior studies ${ }^{2,13}$ we included as covariates sex, age at retirement, marital status (married/cohabiting vs. other), occupational class (high=ISCO occupational classes 1-4 vs. low=ISCO occupational classes 5-9), smoking status (current smoker vs. other), obesity (BMI $\geq 30=$ obese vs. $\mathrm{BMI}<30=$ non-obese), and chronic diseases 
(no vs. any of the following: diabetes, coronary heart disease, cancer, rheumatoid arthritis, and asthma).

\section{Statistical analyses}

Repeated measures regression models with negative binomial distribution were fitted to examine the ratio between the average annual sum of DDDs (i.e. rate) for psychotropic medication before and after the transition to disability retirement among people with high vs. low levels of pre-retirement ERI. We used a generalized estimating equation (GEE) approach with GENMOD procedure in SAS with an exchangeable correlation structure that considers intra-individual correlations between repeated measurements. This approach seeks to measure the effect of disability retirement - removal of work-related stress captured by ERI - while controlling for unobserved heterogeneity. We used difference-in-difference design that The method relies on the assumption of a "parallel trend" which requires that in the absence of a treatment, the difference between the 'treatment' and 'control' group is constant over

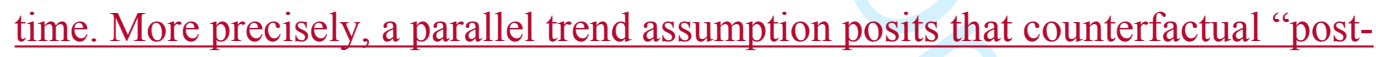
exposure" (i.e. after disability retirement) time trends of the outcome (i.e. psychotropic medication use) would have been identical in the exposed and unexposed groups, that is states that time trends for the psychotropic medication use would have been identicatin the high and low level ERI groups in the absence of the disability retirement. Two models were fitted: Model 1 included sex, age at retirement, pre-retirement ERI status (high vs. low), period (pre- vs. post-retirement), and the interaction between the ERI status and period. The interaction term was fitted to examine whether change in medication use from pre- to post-retirement was different among those with high vs. low level of ERI. Model 2 was further adjusted 
for marital status, occupational class, smoking status, obesity and chronic diseases measured before retirement. The results are presented as rate ratios (RR) with $95 \%$ confidence intervals (CI). All analyses were performed with statistical software SAS. $^{20}$

\section{Results}

Most of the analytical sample (80\%) were female, and 30\% reported a high level of ERI before retirement. Those with a high level of pre-retirement ERI were slightly younger compared to those reporting a low level of ERI. The mean age at retirement due to disability was $54.4(\mathrm{SD}=6.2)$ years for those with high $\mathrm{ERI}$, and $54.6(\mathrm{SD}=6.2)$ for those with low ERI. Corresponding mean ages for the mental disorder group were $52.8(\mathrm{SD}=6.7)$ and $52.2(\mathrm{SD}=7.4)$ years, for the musculoskeletal disease group 55.6 $(\mathrm{SD}=5.4)$ and $55.9(\mathrm{SD}=5.2)$ years, and for the other diseases group $54.0(\mathrm{SD}=6.5)$ and $54.5(\mathrm{SD}=6.2)$ years. Mean levels of DDDs for psychotropic medication in the last survey before disability retirement (on average 2.7 years before retirement) were $213(\mathrm{SD}=417)$ for any cause, $538(\mathrm{SD}=559)$ for mental disorders, $89(\mathrm{SD}=258)$ for musculoskeletal diseases, and $139(\mathrm{SD}=323)$ for other causes. Other descriptive statistics by cause of disability retirement and pre-retirement ERI status are provided in Table 1.

When we examined the impact of all-cause disability retirement, the level of DDDs for psychotropic medications increased before disability retirement while the post-retirement level of use remained stable (Figure 2a). This was true regardless of the ERI status. Among those retiring due to a mental disorder, the increase in the level of DDDs before retirement was much greater than for the other causes (Figure 2b). Those with high level of ERI reached a mean DDD level of 545 in the year before 
retirement, but the level decreased by over 110 DDDs by the third year postretirement. In contrast, among those with a low level of ERI the corresponding decrease in the mean level was smaller; 40 DDD.

Among those retiring for disability due to a musculoskeletal disease, the level of DDDs was non-significantly lower among those with a high (vs. low) level of ERI during pre- and post-retirement periods (Figure 2c). Level of DDDs among those retiring for other causes of disability was higher and it increased steeper around retirement (from -1 to 1) among those with high (vs. low) level of ERI (Figure 2d). While the post-retirement level of DDDs remained stable among those with high ERI, it continued to slowly increase among those with low ERI.

Table 2 presents the rate ratios for the annual sum of DDDs for psychotropic medications for the two- to five-year follow-up periods before and after disability retirement for those with high (vs. low) ERI. The mean level of DDDs before any disability retirement was higher among those with high (vs. low) ERI (RR 1.18, 95\% CI 0.99-1.40). This association was not observed for the post-retirement period, but the interaction between ERI status and period was non-significant $(p>0.11)$. Before disability retirement due to a mental disorder, those with a high (vs. low) level of ERI had a higher level of medication use (RR 1.14, 95\% CI 0.94-1.37), but this difference was not observed post-retirement (RR 0.94, 95\% CI 0.80-1.10) (interaction between ERI status and period $\mathrm{p}=0.02$ ). Those with high and low ERI did not differ in terms of the change in psychotropic medication use around the transition to disability retirement due to musculoskeletal disease or other causes (test of interaction $\mathrm{p}>0.3$ ). Parameter estimates from negative binomial regression model for all covariates are presented in Supplemental Table 1. 


\section{Discussion}

Our findings suggest that pre-retirement perceived work-related stress slightly modifies changes in psychotropic medication use over the transition to disability retirement due to mental disorders. Pre-retirement differences in medication use attenuated after retirement suggesting a larger decrease in post-retirement medication use among those with high vs. low levels of pre-retirement perceived work-related stress. A similar modification was not observed among those retiring for disability due to musculoskeletal diseases or other causes.

We observed a steep increase in the mean level of DDDs for psychotropic medications before disability retirement due to mental disorders both among those with high and low levels of pre-retirement ERI, which agrees with earlier findings. ${ }^{2-5}$ Indeed, those with worsening mental health are likely to increase medication use, which is followed by admittance of disability pension and transition into disability retirement. This increase may also be explained by intensified treatment or rehabilitation activities when there is a threat of losing work ability. In Finland, disability retirement is usually preceded by a 300-day sickness absence period during which medical and vocational rehabilitation are initiated. ${ }^{21}$ There was a difference in the pre-retirement rate of psychotropic medication use between participants reporting high vs. low levels of pre-retirement ERI and the trends of psychotropic medication use over time were parallel during employment. This difference attenuated after disability retirement due to mental disorders adding to the evidence of the beneficial effects of retirement on mental health., ${ }^{9,12}$ Our findings suggest that disability retirement due to mental disorders is particularly beneficial for those suffering from work-related stress. The parallelSimilar trends in the rates of medication use before disability retirement also suggest that the assumption for parallel trends was plausible 
and the method we used to examine the association of removal of perceived workrelated stress with psychotropic medication use was feasibleis valid.

Similar differences in the changes in medication use by ERI status were not observed among those retiring for disability due to musculoskeletal causes. In this group, the levels of psychotropic medication use were very similar regardless of the pre-retirement ERI status, both before and after retirement. These findings differ from those of a prior Finnish study, that did not distinguish between the stressed and nonstressed, where psychotropic medication use slightly increased after disability retirement due to other causes than mental disorders. ${ }^{4}$ However, in our data, among those with disability retirement due to other than mental disorder or musculoskeletal disease and no pre-retirement work stress, there was a small increase in the level of psychotropic use after retirement. This suggests that there may have been other postretirement stressors affecting mental health (and medication use), such as financial strain due to the Great Recession between 2007 and 2009.22

Among those retiring for other than mental or musculoskeletal causes the difference in the level of DDDs for psychotropic medications between those with high vs. low ERI was significant both in the pre- and post-retirement periods. This suggests that cessation of perceived work-related stress had little beneficial effects on mental health in the group retiring for disability due to other causes. That differences were not observed may be due to the heterogenous nature of this group with most common disease groups being cancers (malignant tumours) and cardiovascular diseases.

There are some limitations to this study. The study population was female dominated and worked in the public sector that may limit the generalizability of the findings to male dominated populations or other work sectors. The generalizability of these findings to other cultures may be limited. For example, the observed mental 
health benefits of transferring to different types of retirement have been reported mainly in studies based on European study populations ${ }^{2-5}$ but similar benefits were not observed in studies from the Asian region. ${ }^{7,8}$ We did not have any information on the health care use of the cohort participants, i.e., if they received psychotherapy, counselling or other forms of support for their health problems. Moreover, the observed benefits among those suffering from mental health problems may be underestimations because ERI may not capture all aspects of perceived work-related stress. According to the ERI model, stress results from a perceived imbalance between high efforts at work combined with low rewards in terms of money, esteem, and career opportunities including job security. This concept does not include stressful aspects of work that are unrelated to high efforts, such as bullying or low organizational justice. ${ }^{23,24}$ The main strengths of this study are the register-based outcome data that is not affected by reporting bias, and possibility to control for possible individual-level confounders including health behaviours. We also had a rather long follow-up for the medication use both before and after retirement that increases the validity of the effect estimates.

In summary, pre-retirement perceived work-related stress modified the changes in the rates of psychotropic medication use over transition to disability retirement due to mental disorders. The rate of post-retirement medication use decreased more among those with high than low levels of pre-retirement perceived stress, suggesting that relief of work-related stressors is beneficial for those suffering from mental health problems. Our findings also indicate that it would be important to pay attention to the level of work stress among those employees who use psychotropic medication, so that their early exit from paid employment could be prevented and work careers extended. Changes in psychotropic medication use were not modified by 
perceived work-related stress among those retiring for disability due to musculoskeletal diseases or other causes.

\section{Funding}

This research was funded by the Finnish Academy (grant numbers 287488, 294096 and 319200 for TL and JIH, and grant numbers 286294 and 319246 for SS). MM was supported by the Finnish Work Environment Fund (grant number 115182) and Juho Vainio foundation.

\section{Conflict of interest}

The authors declare no conflict of interests 


\section{Key points}

- The decrease in the level of psychotropic medication after transition to disability retirement due to mental disorders was more pronounced among people who reported perceived work-related stress before retirement, as compared to those without work stress.

- This suggests that relief of work-related stressors is beneficial for those suffering from mental health problems, and that focusing on the level of work stress among employees using psychotropic medication could help reduce the medication use.

- Modification by perceived work-related stress was not present among those retiring for disability due to musculoskeletal diseases or other causes. 


\section{References}

1 Statistics Finland: http://findikaattori.fi/en/76 Accessed Oct 22, 2018.

2 Oksanen T, Vahtera J, Westerlund H, et al. Is retirement beneficial for mental health?: antidepressant use before and after retirement. Epidemiology 2011;22:553-559.

3 Leinonen T, Lahelma E, Martikainen P. Trajectories of antidepressant medication before and after retirement: the contribution of socio-demographic factors. Eur J Epidemiol 2013;28:417-426.

4 Laaksonen M, Metsa-Simola N, Martikainen P, et al. Trajectories of mental health before and after old-age and disability retirement: a register-based study on purchases of psychotropic drugs. Scand J Work Environ Health 2012;38:409-417.

5 Rahman S, Wiberg M, Alexanderson K, Jokinen J, Tanskanen A, Mittendorfer-Rutz E. Trajectories of antidepressant medication use in individuals before and after being granted disability pension due to common mental disorders- a nationwide register-based study. BMC psychiatry 2018;18:47.

6 Sugihara Y, Sugisawa H, Shibata H, Harada K. Productive roles, gender, and depressive symptoms: evidence from a national longitudinal study of latemiddle-aged Japanese. J Gerontol B Psychol Sci Soc Sci 2008;63:P227-p234.

7 Shiba K, Kondo N, Kondo K, Kawachi I. Retirement and mental health: dose social participation mitigate the association? A fixed-effects longitudinal analysis. BMC Public Health 2017;17:526.

8 Schwingel A, Niti MM, Tang C, Ng TP. Continued work employment and volunteerism and mental well-being of older adults: Singapore longitudinal ageing studies. Age Ageing 2009;38:531-537.

9 Westerlund H, Vahtera J, Ferrie JE, et al. Effect of retirement on major chronic conditions and fatigue: French GAZEL occupational cohort study. Bmj 2010;341:c6149.

10 Vahtera J, Westerlund H, Hall M, et al. Effect of retirement on sleep disturbances: the GAZEL prospective cohort study. Sleep 2009;32:1459-1466.

11 Myllyntausta S, Salo P, Kronholm E, et al. Changes in Sleep Difficulties During the Transition to Statutory Retirement. Sleep 2018;41.

12 Jokela M, Ferrie JE, Gimeno D, et al. From midlife to early old age: health trajectories associated with retirement. Epidemiology 2010;21:284-290.

13 Westerlund H, Kivimaki M, Singh-Manoux A, et al. Self-rated health before and after retirement in France (GAZEL): a cohort study. Lancet 2009;374:1889-1896.

14 Barrech A, Riedel N, Li J, et al. The long-term impact of a change in EffortReward imbalance on mental health-results from the prospective MAN-GO study. Eur J Public Health 2017;27:1021-1026.

15 Rugulies R, Aust B, Madsen IE. Effort-reward imbalance at work and risk of depressive disorders. A systematic review and meta-analysis of prospective cohort studies. Scand J Work Environ Health 2017;43:294-306.

16 WHO Collaborating Centre for Drug Statistics Methodology: https://www.whocc.no/ddd/definition and general considera/. 
17 Siegrist J, Wege N, Puhlhofer F, Wahrendorf M. A short generic measure of work stress in the era of globalization: effort-reward imbalance. Int Arch Occup Environ Health 2009;82:1005-1013.

18 Juvani A, Oksanen T, Salo P, et al. Effort-reward imbalance as a risk factor for disability pension: the Finnish Public Sector Study. Scand J Work Environ Health 2014;40:266-277.

19 Dragano N, Siegrist J, Nyberg ST, et al. Effort-Reward Imbalance at Work and Incident Coronary Heart Disease: A Multicohort Study of 90,164 Individuals. Epidemiology 2017;28:619-626.

20 SAS Institute Inc. software release 9.4. Cary, NC: SAS Institute Inc., 2015.

21 Finnish Center for Pensions: https://www.etk.fi/en/the-pensionsystem/pension-security/earnings-related-pension-benefits/disability-pension/ Accessed October 29, 2018.

22 Wilkinson LR. Financial Strain and Mental Health Among Older Adults During the Great Recession. J Gerontol B Psychol Sci Soc Sci 2016;71:745754.

23 Kivimaki M, Vahtera J, Elovainio M, Virtanen M, Siegrist J. Effort-reward imbalance, procedural injustice and relational injustice as psychosocial predictors of health: complementary or redundant models? Occup Environ Med 2007;64:659-665.

24 Kivimaki M, Virtanen M, Vartia M, Elovainio M, Vahtera J, KeltikangasJarvinen L. Workplace bullying and the risk of cardiovascular disease and depression. Occup Environ Med 2003;60:779-783. 
Table 1. Baseline characteristics (\%) of the study population and by the level of preretirement effort reward imbalance (ERI), and by type of disability retirement.

\begin{tabular}{lccc}
\hline & All & High ERI & Low ERI \\
\hline & $\%$ & $\%$ & $\%$ \\
\cline { 2 - 4 } Any disability retirement $(N)$ & 2766 & 835 & 1931 \\
Sex (female) & 84 & 84 & 83 \\
Not married or cohabiting & 27 & 29 & 26 \\
Low occupational class & 58 & 59 & 58 \\
Smoking & 24 & 27 & 22 \\
Obese & 21 & 20 & 22 \\
At least one chronic disease & 20 & 20 & 20 \\
DDD $>30^{*}$ & 45 & 50 & 43 \\
Disability due to mental disorders $(N)$ & 686 & 241 & 446 \\
Sex (female) & 86 & 83 & 88 \\
Not married or cohabiting & 32 & 34 & 32 \\
Low occupational class & 43 & 41 & 44 \\
Smoking & 25 & 30 & 23 \\
Obese & 20 & 22 & 20 \\
At least one chronic disease & 14 & 16 & 13 \\
DDD $>30^{*}$ & 88 & 91 & 87 \\
Disability due to musculoskeletal diseases (N) & 1282 & 386 & 896 \\
Sex (female) & 85 & 85 & 85 \\
Not married or cohabiting & 25 & 25 & 25 \\
Low occupational class & 71 & 75 & 69 \\
Smoking & 22 & 22 & 22 \\
Obese & 24 & 21 & 25 \\
At least one chronic disease & 20 & 20 & 20 \\
DDD $>30^{*}$ & 25 & 26 & 25 \\
Disability due to other diseases (N) & 797 & 208 & 589 \\
Sex (female) & 79 & 82 & 77 \\
Not married or cohabiting & 26 & 28 & 25 \\
Low occupational class & 50 & 49 & 50 \\
Smoking & 25 & 31 & 23 \\
Obese & 18 & 16 & 18 \\
At least one chronic disease & 26 & 24 & 26 \\
DDD $>30 *$ & 40 & 47 & 38 \\
\hline
\end{tabular}

*proportion of those with sum of annual defined daily dose $>30$ 
Table 2. Rate ratios (RR) of psychotropic medication annual daily defined dose (DDD) before and after disability retirement among people with high versus low level of preretirement effort reward imbalance (ERI).

\begin{tabular}{|c|c|c|c|c|c|}
\hline \multirow[b]{2}{*}{ Disability retirement } & \multicolumn{2}{|c|}{ Pre-retirement } & \multicolumn{2}{|c|}{ Post-retirement } & \multirow{2}{*}{$\begin{array}{l}\text { p-value for interaction } \\
\text { term ERI status }{ }^{*} \text { period }{ }^{1}\end{array}$} \\
\hline & RR & $95 \% \mathrm{CI}$ & RR & $95 \% \mathrm{CI}$ & \\
\hline \multicolumn{6}{|l|}{ Due to any cause } \\
\hline Low ERI & 1 & & 1 & & \\
\hline High ERI - Model $1^{2}$ & 1.26 & $1.05-1.52$ & 1.13 & $0.97-1.31$ & 0.08 \\
\hline High ERI - Model $2^{3}$ & 1.18 & $0.99-1.40$ & 1.07 & $0.92-1.24$ & 0.11 \\
\hline \multicolumn{6}{|c|}{ Due to mental disorders (ICD F00-99) } \\
\hline Low ERI & 1 & & 1 & & \\
\hline High ERI - Model $1^{2}$ & 1.21 & $0.98-1.51$ & 0.99 & $0.83-1.18$ & 0.02 \\
\hline High ERI - Model $2^{3}$ & 1.14 & $0.94-1.37$ & 0.94 & $0.80-1.10$ & 0.02 \\
\hline \multicolumn{6}{|c|}{ Due to musculoskeletal diseases (ICD M00-99) } \\
\hline Low ERI & 1 & & 1 & & \\
\hline High ERI - Model $1^{2}$ & 0.73 & $0.51-1.04$ & 0.78 & $0.58-1.04$ & 0.66 \\
\hline High ERI - Model $2^{3}$ & 0.79 & $0.54-1.15$ & 0.83 & $0.61-1.12$ & 0.71 \\
\hline \multicolumn{6}{|l|}{ Due to all other causes } \\
\hline Low ERI & 1 & & 1 & & \\
\hline High ERI - Model $1^{2}$ & 1.65 & $1.13-2.42$ & 1.49 & $1.08-2.04$ & 0.38 \\
\hline High ERI - Model $2^{3}$ & 1.53 & $1.07-2.18$ & 1.36 & $1.02-1.82$ & 0.32 \\
\hline
\end{tabular}

${ }^{1}$ Shows if the change in the level of DDD from pre- to post-retirement period is different among people reporting high vs. low level of pre-retirement effort-reward imbalance ${ }^{2}$ Model includes sex, age at retirement, ERI status (high vs. low level of ERI), period (postvs. pre-retirement), and ERI status*period

${ }^{3}$ Model includes sex, age at retirement, marital status, occupational class, smoking, obesity, chronic diseases, ERI status (high vs. low level of ERI), period (post- vs. pre-retirement), and ERI status*period 
3279 eligible as retired due to disability between 2000 and 2009

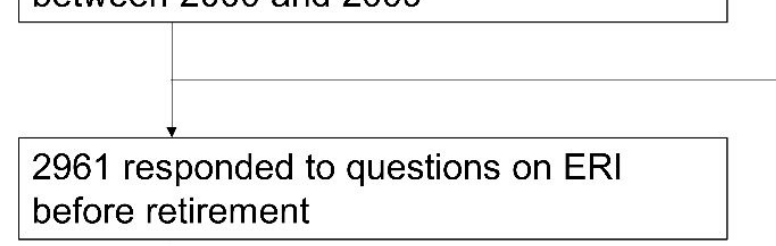
reward imbalance (ERI) before retirement

Figure 1. Flow chart of the sample selection.

\section{5 had no information on all covariates}

2766 participants with information on ERI and all covariates 

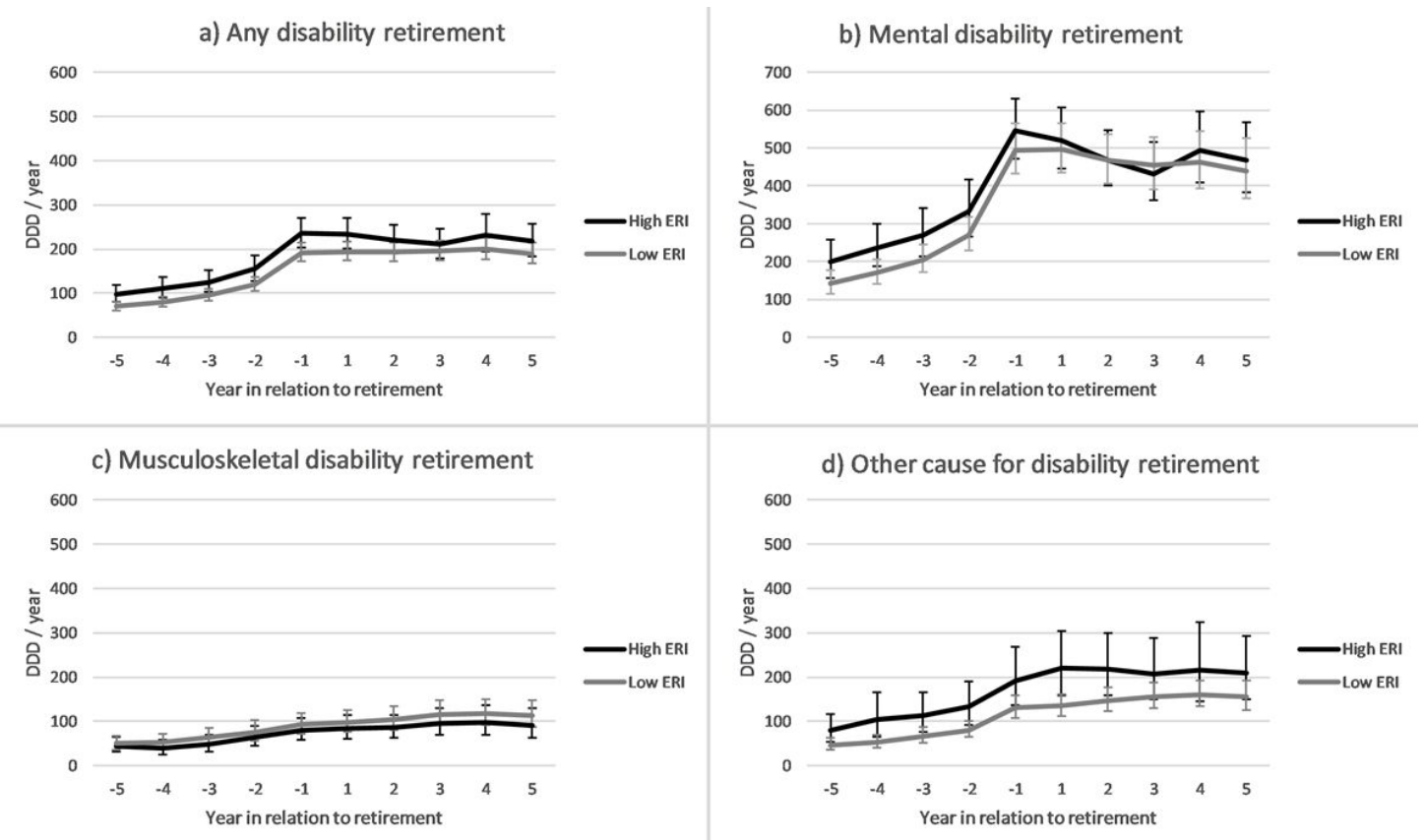

Figure 2. Age at retirement- and sex-adjusted level of defined daily doses (DDD) for psychotropic medications by level of effort-reward imbalance (ERI) in relation to year of disability retirement due to a) any cause of disability, b) mental disorders, c) musculoskeletal disease, and d) other causes. 


\section{Supplemental material}

\section{Psychotropic medication before and after disability retirement by pre- retirement perceived work-related stress}

Halonen JI, Chandola T, Hyde M, Leinonen T, Westerlund H, Aalto V, Pentti J, Laaksonen M, Stenholm S, Mänty M, Vahtera J, Oksanen T, Kivimäki M, Virtanen M, Lallukka T 
Supplemental Table 1. Generalized estimating equation parameter estimates from negative binomial regression analyses.

\begin{tabular}{|c|c|c|c|c|}
\hline \multirow{2}{*}{$\begin{array}{l}\text { Disability retirement } \\
\text { Due to any cause }\end{array}$} & \multirow[t]{2}{*}{ Beta } & \multicolumn{2}{|c|}{$95 \% \mathrm{CI}$} & \multirow[t]{2}{*}{ p-value } \\
\hline & & & & \\
\hline Intercept & 8.33 & 7.76 & 8.89 & $<0.001$ \\
\hline Age & -0.05 & -0.06 & -0.04 & $<0.001$ \\
\hline Sex (men vs. women) & -0.09 & -0.29 & 0.11 & 0.37 \\
\hline Married (vs. not) & -0.22 & -0.37 & -0.06 & 0.01 \\
\hline Low occupational class (vs. not) & 0.41 & 0.26 & 0.55 & $<0.001$ \\
\hline Smoker (vs. not) & 0.63 & 0.45 & 0.80 & $<0.001$ \\
\hline Obese (vs. not) & 0.06 & -0.11 & 0.23 & 0.49 \\
\hline Chronic diesease & -0.22 & -0.39 & -0.05 & 0.01 \\
\hline High ERI & 0.06 & -0.08 & 0.21 & 0.39 \\
\hline Period (pre vs. post) & -0.56 & -0.64 & -0.49 & $<0.001$ \\
\hline ERI*period & 0.10 & -0.02 & 0.21 & 0.10 \\
\hline \multicolumn{5}{|c|}{ Due to mental disorders (ICD F00-99) } \\
\hline Intercept & 7.55 & 7.04 & 8.07 & $<0.001$ \\
\hline Sex (men vs. women) & -0.25 & -0.46 & -0.03 & 0.02 \\
\hline Age & -0.03 & -0.04 & -0.02 & $<0.001$ \\
\hline Married (vs. not) & -0.03 & -0.20 & 0.14 & 0.70 \\
\hline Low occupational class & -0.06 & -0.22 & 0.09 & 0.43 \\
\hline Smoker (vs. not) & 0.59 & 0.40 & 0.77 & $<0.001$ \\
\hline Obese (vs. not) & 0.04 & -0.15 & 0.24 & 0.67 \\
\hline Chronic diesease & -0.13 & -0.34 & 0.08 & 0.21 \\
\hline High ERI & -0.06 & -0.22 & 0.10 & 0.47 \\
\hline Period (pre vs. post) & -0.60 & -0.70 & -0.51 & $<0.001$ \\
\hline ERI*period & 0.19 & 0.04 & 0.33 & 0.01 \\
\hline \multicolumn{5}{|c|}{ Due to musculoskeletal diseases (ICD M00-99) } \\
\hline Intercept & 6.48 & 4.76 & 8.20 & $<0.001$ \\
\hline Sex (women vs. men) & 0.11 & -0.35 & 0.57 & 0.64 \\
\hline Age & -0.03 & -0.06 & 0.00 & 0.07 \\
\hline Married (vs. not) & -0.34 & -0.67 & -0.01 & 0.04 \\
\hline Low occupational class & -0.29 & -0.63 & 0.04 & 0.08 \\
\hline Smoker (vs. not) & 0.49 & 0.12 & 0.86 & 0.01 \\
\hline Obese (vs. not) & 0.06 & -0.28 & 0.40 & 0.73 \\
\hline Chronic diesease & -0.26 & -0.62 & 0.10 & 0.15 \\
\hline High ERI & -0.19 & -0.50 & 0.11 & 0.22 \\
\hline Period (pre vs. post) & -0.46 & -0.63 & -0.28 & $<0.001$ \\
\hline ERI*period & -0.05 & -0.30 & 0.20 & 0.71 \\
\hline \multicolumn{5}{|l|}{ Due to all other causes } \\
\hline Intercept & 6.25 & 5.25 & 7.25 & $<0.001$ \\
\hline Sex (women vs. men) & 0.19 & -0.16 & 0.55 & 0.29 \\
\hline Age & -0.02 & -0.04 & -0.01 & 0.01 \\
\hline Married (vs. not) & -0.15 & -0.44 & 0.13 & 0.29 \\
\hline Low occupational class & -0.22 & -0.49 & 0.05 & 0.11 \\
\hline Smoker (vs. not) & 0.62 & 0.30 & 0.95 & $<0.01$ \\
\hline Obese (vs. not) & 0.09 & -0.26 & 0.44 & 0.61 \\
\hline Chronic diesease & 0.07 & -0.22 & 0.35 & 0.65 \\
\hline High ERI & 0.31 & 0.02 & 0.60 & 0.04 \\
\hline Period (pre vs. post) & -0.69 & -0.81 & -0.56 & $<0.001$ \\
\hline ERI*period & 0.11 & -0.10 & 0.33 & 0.30 \\
\hline
\end{tabular}


